\title{
Prognostic Factors of Patients with Left-sided Obstructive Colorectal Cancer: Post-hoc Analysis of a Retrospective Multi-center Study in the Japan Colonic Stent Safe Procedure Research Group
}

Shungo Endo ( $\nabla$ endoswing@gmail.com )

Fukushima Medical University Aizu Medical Center: Fukushima Kenritsu Ika Daigaku Aizu Iryo Center https://orcid.org/0000-0003-2383-8407

Noriyuki Isohata

Fukushima Medical University Aizu Medical Center: Fukushima Kenritsu Ika Daigaku Aizu Iryo Center Koichiro Kojima

Kyorin University: Kyorin Daigaku

\section{Yoshihiro Kadono}

Saiseikai Kumamoto Hospital: Saiseikai Kumamoto Byoin

\section{Kunihiko Amano}

Saitama Medical University: Saitama Ika Daigaku

\section{Hideo Otsuka}

Tokyo Metropolitan Tama Medical Center: Tokyo Toritsu Tama Sogo Iryo Center

Tatsuya Fujimoto

Kimitsu Chuo Hospital: Kimitsu Chuo Byoin

\section{Hideto Egashira}

Shonan Kamakura General Hospital: Shonan Kamakura Sogo Byoin

\section{Yoshihisa Saida}

Toho University Medical Center Ohashi Hospital: Toho Daigaku Iryo Center Ohashi Byoin

\section{Research article}

Keywords: Obstructive colorectal cancer, Emergency surgery, Self-expandable metallic stent, Relapse-free survival, Prognostic factor, Stage migration

Posted Date: September 29th, 2021

DOl: https://doi.org/10.21203/rs.3.rs-919306/v1

License: (c) (1) This work is licensed under a Creative Commons Attribution 4.0 International License. Read Full License 
Page $2 / 20$ 


\section{Abstract \\ Background}

There are many reports on the choice of treatment and prognosis of left-sided obstructive colorectal cancer; only few studies focus on the prognostic factors of LOCRC. Therefore, we analyzed the prognostic factors of left-sided obstructive colorectal cancer by post-hoc analysis of a retrospective multicenter study in the Japan Colonic Stent Safe Procedure Research Group.

\section{Methods}

This study was conducted as a post-hoc analysis of a retrospective multi-center observational study which enrolled a total of 301 patients, with the aim of investigating prognostic factors for relapse-free survival. The relationships among sex, age, decompression for bridge to surgery, depth of invasion, lymph node metastasis, postoperative complications, adjuvant chemotherapy, carcinoembryonic antigen, carbohydrate antigen $19-9$, neutrophil-to-lymphocyte ratio, and relapse-free survival were examined.

\section{Results}

T3 of depth of invasion, negative postoperative complication (grade $0-1$ of Clavien-Dindo classification), and administration of adjuvant chemotherapy (in Stage III) indicated a significantly good prognosis using Cox's univariate analyses. Lymph node metastasis was not selected as a prognostic factor. Then, excluding patients with $<12$ harvested lymph nodes, which may indicate stage migration, lymph node metastasis was also determined to be a prognostic factor. Using Cox's multivariate analysis, depth of invasion, lymph node metastasis (excluding NO cases with $<12$ harvested lymph nodes), and adjuvant chemotherapy (all cases) were found to be prognostic factors.

\section{Conclusions}

In left-sided obstructive colorectal cancer, depth of invasion, lymph node metastasis and adjuvant chemotherapy were found to be prognostic factors, and patients with $<12$ dissected lymph nodes could cause stage migration. This may result in disadvantages, such as not being able to receive adjuvant chemotherapy.

\section{Introduction}

Colorectal cancer (CRC) is the third most commonly diagnosed malignancy, accounting for approximately 1.4 million new cases per year. It represents the third most common cancer in men ( 746,000 cases, $10.0 \%$ of the total) and the second most common cancer in women $(614,000$ cases, $9.2 \%$ 
of the total) worldwide; it is the fourth leading cause of cancer-related deaths worldwide, with almost 700,000 deaths in 2012 [1, 2].

Large bowel obstruction represents almost $80 \%$ ( $15 \%-30 \%$ of CRCs) of emergencies related to CRC, while perforation accounts for the remaining $20 \%$ ( $1 \%-10 \%$ of CRC cases) [3-6]. The most common location of obstructive CRC is the sigmoid colon, with $75 \%$ of the tumors located distal to the splenic flexure [7]. Obstructive right-sided colon cancer is usually treated by emergency surgery with primary resection and ileocolic anastomosis [8]; however, it is controversial whether emergency or radical surgery after decompression for "bridge to surgery (BTS)" for left-sided obstructive colorectal cancer (LOCRC) is to be considered [9]. The short-term outcomes of BTS using self-expandable metallic stent (SEMS) were excellent, but long-term oncological outcomes have been questioned. However, in recent years, an increasing number of reports have shown that the long-term outcomes of emergency and elective surgeries after decompression using SEMS are equivalent [10-13].

Although there are many reports on the choice of treatment and prognosis of LOCRC, there are only few studies on the prognostic factors of LOCRC [14]. Therefore, we analyzed the prognostic factors of LOCRC by post-hoc analysis of a retrospective multi-center observational study in Japan that comparison of the survival and perioperative outcomes of the colonic stent and the transanal decompression tube placement and emergency surgery for left-sided obstructive colorectal cancer (CODOMO study) [15].

\section{Methods}

\section{Study design and participants}

The CODOMO study was conducted in the Japan Colonic Stent Safe Procedure Research Group; its study design, eligibility criteria, and treatment parameters have been reported previously [15]. This study was conducted as a post-hoc analysis of the CODOMO study, with the aim of investigating prognostic factors for RFS. The medical ethics committee of Fukushima Medical University reviewed and approved the observational study design, informed consent was waived. This study was also registered in the Japan University Hospital Medical Information Network Clinical Trial Registry (UMIN000024488). In brief, the CODOMO study was a retrospective, multi-center, observational study comparing RFS and perioperative outcomes of colonic stenting, transanal decompression tube placement, and emergency surgery for LOCRC. The subjects were patients with histologically proven stage II/III left-sided colon or upper rectal cancer with obstruction, who underwent subsequent surgery with curative resection between January 2010 and December 2014. The definition of the obstruction was specified based on the ColoRectal Obstruction Scoring System (CROSS) [14]; patients with CROSS 0 (requiring continuous decompression) and 1 (no oral intake) were included. The patients' ages ranged from 20 to 80 years; those treated with neoadjuvant chemotherapy and/or radiation therapy were excluded. Subsequently, 301 patients from 27 institutions met the criteria. Patients were divided into three groups based on the decompression procedures: the Surgery group with decompression by colostomy or intraoperative decompression during radical surgery (emergency surgery, $n=103$ ), the SEMS group using SEMS for BTS $(n=113)$, and the 
transanal decompression tube (TADT) group with decompression using TADT for BTS $(n=85)$. There were 23 patients in the Surgery group who underwent two-step surgery for stoma creation and curative resection for LOCRC which is one of the techniques of bridging to surgery (Fig. 1). In conclusions of the CODOMO study, patients who underwent SEMS placement for LOCRC had similar oncological outcomes to patients who underwent emergency surgery; the TADT placement for BTS showed significantly lower RFS than those who underwent emergency surgery. Additionally, the total number of complications after curative surgery was significantly lower in the SEMS group than in the Surgery group.

\section{Prognostic Factors (Dup: Abstract ?)}

In this study, the prognostic factors of LOCRC that influence RFS were analyzed. Among the aggregated data, the relationships among sex, age, decompression for BTS, depth of invasion, lymph node metastasis, postoperative complications, adjuvant chemotherapy, preoperative serum CEA level, preoperative serum CA 19 - 9 level, preoperative NLR, and RFS were examined. Patients were divided according to CEA level was $\leq 5 \mathrm{ng} / \mathrm{mL}$, and $>5 \mathrm{ng} / \mathrm{ml}$, and CA $19-9$ was $\leq 37 \mathrm{U} / \mathrm{mL}$, and $>37 \mathrm{U} / \mathrm{mL}$ to examine its association with RFS. NLR was divided by two cutoff levels, one was $\leq 3.0$ and $>3.0$, and the other was $\leq 5.0$ and $>5.0$. Since there is no fixed cutoff value for NLR as a prognostic factor, and some report a cutoff value of $3.0[16,17]$ while others report $5.0[18,19]$, we adopted two cutoff values.

\section{Statistical analysis}

Quantitative data are reported as the median (range). All statistical analyses were performed using SPSS ver. 25 (IBM, Armonk, NY, USA). The Chi-square tests (Fisher's exact tests) was used to compare discrete variables. RFS analysis was conducted using the Kaplan-Meier method and log-rank test to determine the significance of the survival curves. To identify prognostic factors for RFS, the Cox's proportional hazards model was used for univariate and multivariate analyses. Statistical significance was set at $p<$ 0.05 .

\section{Results}

\section{Patient characteristics}

The baseline characteristics of the patients are summarized in Table 1. In this study, all patients were Japanese, with a median age of 69 years and a range of 28 to 80 years. Most of the patients were good generally in good condition, with an Eastern Cooperative Oncology Group (ECOG) performance status of 0 to 1 in $87.0 \%$ of cases. Tumor locations were all in the left-sided colon, with $20.9 \%$ in the descending colon, $69.8 \%$ in the sigmoid colon, and $9.3 \%$ in the upper rectum. Decompression methods for BTS were as follows: stoma creation, $7.6 \%$; SEMS, $37.5 \%$; and TADT, $28.2 \%$; however, emergency operation with intraoperative decompression was $26.6 \%$. There was only one case with T2; however, other cases were T3 or T4 in depth of invasion. In order to ensure high quality in staging colon cancer, national guidelines 
recommend histopathological evaluation of at least 12 lymph nodes [20]. The number of harvested lymph nodes should be $\geq 12$ to prevent stage migration [21, 22], but $<12$ were dissected in $19.9 \%$ of cases. The administration rate of adjuvant chemotherapy for Stage III cases was significantly higher than that of Stage II cases. Postoperative complications were graded according to the Clavien-Dindo classification [23] of 0 to 1 in $72.8 \%$ of cases and 2 to 5 in $27.2 \%$ of cases. There were missing values for preoperative CEA in 10 patients, CA 19 - 9 in 12 patients, and NLR in 56 patients, owing to the retrospective design of this study. Positive rate of CEA (cutoff level: $5.0 \mathrm{ng} / \mathrm{mL}$ ) and CA $19-9$ (cutoff level: $37 \mathrm{U} / \mathrm{mL}$ ) were $57.4 \%$ and $17.3 \%$, respectively. 
Table 1

Demographical characteristics of the study population.

\begin{tabular}{|c|c|c|c|c|}
\hline Variable & Category & $\mathbf{n}$ & & $(\%)$ \\
\hline Age (years), median (range) & & 69 & $(28-80)$ & \\
\hline \multirow[t]{2}{*}{ Gender } & Male & 176 & & $(58.5)$ \\
\hline & Female & 125 & & $(41.5)$ \\
\hline \multirow[t]{5}{*}{ PS (ECOG) } & 0 & 184 & & $(61.1)$ \\
\hline & 1 & 78 & & $(25.9)$ \\
\hline & 2 & 22 & & (7.3) \\
\hline & 3 & 14 & & $(4.7)$ \\
\hline & 4 & 3 & & $(1.0)$ \\
\hline \multirow[t]{3}{*}{ Tumor location } & Descending colon & 63 & & $(20.9)$ \\
\hline & Sigmoid colon & 210 & & $(69.8)$ \\
\hline & Upper rectum & 28 & & (9.3) \\
\hline \multirow[t]{4}{*}{ Decompression for BTS } & Stoma & 23 & & $(7.6)$ \\
\hline & SEMS & 113 & & $(37.5)$ \\
\hline & TADT & 85 & & $(28.2)$ \\
\hline & No & 80 & & $(26.6)$ \\
\hline \multirow[t]{3}{*}{ Depth of invasion (TNM) } & $\mathrm{T} 2$ & 1 & & $(0.3)$ \\
\hline & T3 & 187 & & $(62.1)$ \\
\hline & $\mathrm{T} 4$ (T4a / T4b) & 113 & $(85 / 28)$ & $(37.5)$ \\
\hline \multirow[t]{3}{*}{ Lymph node metastasis (TNM) } & NO & 164 & & $(54.5)$ \\
\hline & N1 & 109 & & $(36.2)$ \\
\hline & N2 & 28 & & $(9.3)$ \\
\hline \multirow[t]{2}{*}{ Number of harvested lymph nodes } & $<12$ & 60 & & $(19.9)$ \\
\hline & $\geq 12$ & 241 & & $(80.1)$ \\
\hline Stage (TNM) & II (IIA / IIB / IIC) & 164 & $(100 / 48 / 16)$ & $(54.5)$ \\
\hline
\end{tabular}

PS (ECOG) performance status (Eastern Cooperative Oncology Group), BTS bridge to surgery, SEMS self-expanding metallic stent, TADT transanal decompression tube, CEA carcinoembryonic antigen, CA $19-9$ carbohydrate antigen $19-9, N L R$ neutrophil-to-lymphocyte ratio, * Administration rate of adjuvant chemotherapy was significantly higher in Stage III than in Stage II by Fisher's exact test 


\begin{tabular}{|c|c|c|c|}
\hline Variable & Category & $\mathrm{n}$ & $(\%)$ \\
\hline & III (IIIA / IIIB / IIIC) & $137 \quad(1 / 110 / 26)$ & $(45.5)$ \\
\hline \multirow[t]{2}{*}{ Adjuvant chemotherapy* } & Stage II & 51 & $(31.1)$ \\
\hline & Stage III & 97 & $(70.8)$ \\
\hline Postoperative complication & 0 & 217 & $(72.1)$ \\
\hline \multirow[t]{5}{*}{ (Clavien-Dindo classification) } & 1 & 2 & $(0.7)$ \\
\hline & 2 & 47 & $(15.6)$ \\
\hline & 3 & 28 & $(9.3)$ \\
\hline & 4 & 3 & $(1.0)$ \\
\hline & 5 & 4 & $(1.3)$ \\
\hline \multirow[t]{3}{*}{ CEA (ng/mL) } & Not measured & 10 & (3.3) \\
\hline & $\leq 5$ & 124 & $(41.2)$ \\
\hline & $>5$ & 167 & $(55.4)$ \\
\hline \multirow[t]{3}{*}{ CA $19-9(\mathrm{U} / \mathrm{mL})$} & Not measured & 12 & $(4.0)$ \\
\hline & $\leq 37$ & 239 & $(79.4)$ \\
\hline & $>37$ & 50 & $(16.6)$ \\
\hline \multirow[t]{4}{*}{ NLR } & Not measured & 55 & $(18.3)$ \\
\hline & $\leq 3$ & 113 & $(37.5)$ \\
\hline & $3<, \leq 5$ & 75 & $(24.9)$ \\
\hline & $>5$ & 58 & $(19.3)$ \\
\hline \multicolumn{4}{|c|}{$\begin{array}{l}P S(E C O G) \text { performance status (Eastern Cooperative Oncology Group), BTS bridge to surgery, SEMS } \\
\text { self-expanding metallic stent, TADT transanal decompression tube, CEA carcinoembryonic antigen, } \\
C A 19-9 \text { carbohydrate antigen } 19-9, N L R \text { neutrophil-to-lymphocyte ratio, * Administration rate of } \\
\text { adjuvant chemotherapy was significantly higher in Stage Ill than in Stage ll by Fisher's exact test }\end{array}$} \\
\hline
\end{tabular}

When we examined the relationship between the frequency of patients with $<12$ dissected lymph nodes and the status of preoperative decompression, patients who underwent emergency surgery without decompression presented with more cases having $<12$ dissected lymph nodes (Table 2). There were 34 cases with $<12$ harvested lymph nodes in lymph node metastasis-negative cases (N0); therefore, cases with $<12$ harvested lymph nodes were excluded from the NO cases in the analyses of prognostic factors. The Kaplan-Meier curves for depth of invasion and lymph node metastasis are shown in Fig. 2. 
Table 2

Cases $<12$ harvested lymph nodes without/with preoperative decompression

\begin{tabular}{|llll|}
\hline & $\mathrm{n}$ & (\%) & p value \\
\hline Without preoperative decompression $(\mathrm{n}=80)$ & 25 & $(31.3)$ & 0.005 \\
\hline With preoperative decompression $(\mathrm{n}=221)$ & 35 & $(15.8)$ & \\
\hline$P$ value was calculated by Fisher's exact test & & & \\
\hline
\end{tabular}

Prognostic Factors

The candidates for prognostic factors were selected as follows: PS, tumor location, decompression for BTS, depth of invasion, lymph node metastasis, postoperative complication, adjuvant chemotherapy, serum CEA level, serum CA 19 - 9 level, and NLR. Among these factors, T3 of depth of invasion, negative lymph node metastasis (excluding NO cases with $<12$ harvested lymph nodes), negative postoperative complications (grade $0-1$ of CD classification), and administration of adjuvant chemotherapy (in Stage III) indicated a significantly good prognosis using Cox's univariate analyses (Table 3). 
Table 3

Prognostic factors by Cox's univariate analysis for relapse-free survival

\begin{tabular}{|c|c|c|c|c|}
\hline Variable & $\begin{array}{l}\text { Survival (mo) } \\
\text { Av. }(95 \% \mathrm{Cl})\end{array}$ & HR & $95 \% \mathrm{Cl}$ & $\begin{array}{l}p \\
\text { value }\end{array}$ \\
\hline & $\begin{array}{l}\text { Kaplan-Meier } \\
\text { method }\end{array}$ & \multicolumn{2}{|c|}{$\begin{array}{l}\text { Cox's univariate } \\
\text { analysis }\end{array}$} & \\
\hline \multicolumn{5}{|l|}{ PS } \\
\hline $0-1(n=262)$ & $\begin{array}{l}62.0(57.4- \\
66.5)\end{array}$ & 1 & & 0.523 \\
\hline $2-4(n=39)$ & $\begin{array}{l}59.9(48.5- \\
71.2)\end{array}$ & 0.845 & $\begin{array}{l}0.505- \\
1.416\end{array}$ & \\
\hline \multicolumn{5}{|l|}{ Location } \\
\hline Colon $(n=273)$ & $\begin{array}{l}62.1(57.6- \\
66.5)\end{array}$ & 1 & & 0.381 \\
\hline Rectum $(n=28)$ & $\begin{array}{l}57.7(44.2- \\
71.1)\end{array}$ & 0.381 & $\begin{array}{l}0.433- \\
1.377\end{array}$ & \\
\hline \multicolumn{5}{|c|}{ Decompression for BTS } \\
\hline No $(n=80)$ & $\begin{array}{l}63.0(56.0- \\
70.0)\end{array}$ & 1 & & 0.155 \\
\hline Yes $(n=221)$ & $\begin{array}{l}60.7(55.6- \\
65.7)\end{array}$ & 0.724 & $\begin{array}{l}0.463- \\
1.130\end{array}$ & \\
\hline \multicolumn{5}{|c|}{ Depth of invasion } \\
\hline T3 $(n=179)$ & $\begin{array}{l}68.5(63.3- \\
73.7)\end{array}$ & 1 & & $\begin{array}{l}< \\
0.001\end{array}$ \\
\hline $\mathrm{T} 4(\mathrm{n}=121)$ & $\begin{array}{l}49.5(43.2- \\
55.9)\end{array}$ & 0.489 & $\begin{array}{l}0.338- \\
0.708\end{array}$ & \\
\hline \multicolumn{5}{|c|}{ Lymph node metastasis } \\
\hline NO $(n=164)$ & $\begin{array}{l}65.1(59.5- \\
70.7)\end{array}$ & 1 & & 0.177 \\
\hline $\mathrm{N} 1-2(\mathrm{n}=137)$ & $\begin{array}{l}58.4(52.1- \\
64.8)\end{array}$ & 0.776 & $\begin{array}{l}0.536- \\
1.122\end{array}$ & \\
\hline
\end{tabular}

Survival (mo) Av. (95\% Cl) survival periods (months) average and $95 \%$ confidential interval, $H R$ hazard ratio, PS performance status, $B T S$ bridge to surgery, SEMS self-expanding metallic stent, TADT transanal decompression tube, $C E A$ carcinoembryonic antigen, $C A 19-9$ carbohydrate antigen $19-9$, $N L R$ neutrophil-to-lymphocyte ratio 


\begin{tabular}{|c|c|c|c|c|}
\hline Variable & $\begin{array}{l}\text { Survival (mo) } \\
\text { Av. }(95 \% \mathrm{Cl})\end{array}$ & HR & $95 \% \mathrm{Cl}$ & $\begin{array}{l}p \\
\text { value }\end{array}$ \\
\hline N0 $(n=130)$ & $\begin{array}{l}69.3(63.4- \\
75.1)\end{array}$ & 1 & & 0.036 \\
\hline$N 1-2(n=137)$ & $\begin{array}{l}58.9(52.5- \\
65.2)\end{array}$ & 0.644 & $\begin{array}{l}0.427- \\
0.971\end{array}$ & \\
\hline \multicolumn{5}{|c|}{ Postoperative complication } \\
\hline grade $0-I(n=219)$ & $\begin{array}{l}64.9(59.8- \\
69.9)\end{array}$ & 1 & & 0.026 \\
\hline grade II-V $(\mathrm{n}=82)$ & $\begin{array}{l}54.0(45.7- \\
62.3)\end{array}$ & 1.553 & $\begin{array}{l}1.053- \\
2.289\end{array}$ & \\
\hline \multicolumn{5}{|c|}{ Adjuvant chemotherapy } \\
\hline No $(n=153)$ & $\begin{array}{l}60.5(54.6- \\
66.4)\end{array}$ & 1 & & 0.616 \\
\hline Yes $(n=148)$ & $\begin{array}{l}63.9(58.0- \\
69.8)\end{array}$ & 1.048 & $\begin{array}{l}0.872- \\
1.264\end{array}$ & \\
\hline \multicolumn{5}{|c|}{ Adjuvant chemotherapy in Stage II } \\
\hline No $(n=113)$ & $\begin{array}{l}63.8(58.0- \\
69.6)\end{array}$ & 1 & & 0.214 \\
\hline Yes $(n=51)$ & $\begin{array}{l}59.8(49.1- \\
70.6)\end{array}$ & 0.707 & $\begin{array}{l}0.409- \\
1.222\end{array}$ & \\
\hline \multicolumn{5}{|c|}{ Adjuvant chemotherapy in Stage III } \\
\hline No $(n=40)$ & $\begin{array}{l}44.3(32.6- \\
56.0)\end{array}$ & 1 & & 0.003 \\
\hline Yes $(n=97)$ & $\begin{array}{l}63.4(56.7- \\
70.0)\end{array}$ & 2.231 & $\begin{array}{l}1.312- \\
3.791\end{array}$ & \\
\hline \multicolumn{5}{|c|}{ Preoperative serum CEA level (ng/mL) } \\
\hline$\leq 5(n=124)$ & $\begin{array}{l}59.6(54.2- \\
65.0)\end{array}$ & 1 & & 0.224 \\
\hline$>5(n=167)$ & $\begin{array}{l}59.4(53.5- \\
65.2)\end{array}$ & 0.787 & $\begin{array}{l}0.535- \\
1.158\end{array}$ & \\
\hline \multicolumn{5}{|c|}{ Preoperative serum CA 19 - 9 level $(\mathrm{U} / \mathrm{mL})$} \\
\hline$\leq 37(n=239)$ & $\begin{array}{l}63.1(58.3- \\
68.0)\end{array}$ & 1 & & 0.226 \\
\hline \multicolumn{5}{|c|}{$\begin{array}{l}\text { Survival (mo) Av. }(95 \% \mathrm{Cl}) \text { survival periods (months) average and } 95 \% \text { confidential interval, } H R \text { hazard } \\
\text { ratio, } P S \text { performance status, } B T S \text { bridge to surgery, SEMS self-expanding metallic stent, } T A D T \\
\text { transanal decompression tube, CEA carcinoembryonic antigen, } C A 19-9 \text { carbohydrate antigen } 19-9 \text {, } \\
\text { NLR neutrophil-to-lymphocyte ratio }\end{array}$} \\
\hline
\end{tabular}




\begin{tabular}{|c|c|c|c|c|}
\hline Variable & $\begin{array}{l}\text { Survival (mo) } \\
\text { Av. }(95 \% \mathrm{Cl})\end{array}$ & HR & $95 \% \mathrm{Cl}$ & $\begin{array}{l}p \\
\text { value }\end{array}$ \\
\hline$>37(n=50)$ & $\begin{array}{l}53.4(43.9- \\
62.9)\end{array}$ & 0.748 & $\begin{array}{l}0.468- \\
1.196\end{array}$ & \\
\hline \multicolumn{5}{|c|}{ Preoperative NLR } \\
\hline$\leq 3(n=113)$ & $\begin{array}{l}59.4(53.0- \\
65.9)\end{array}$ & 1 & & 0.957 \\
\hline > $3(133)$ & $\begin{array}{l}60.9(54.3- \\
67.5)\end{array}$ & 1.011 & $\begin{array}{l}0.674- \\
1.518\end{array}$ & \\
\hline$\leq 5(n=188)$ & $\begin{array}{l}59.2(54.1- \\
64.3)\end{array}$ & 1 & & 0.798 \\
\hline$>5(n=58)$ & $\begin{array}{l}61.8(52.4- \\
71.2)\end{array}$ & 1.064 & $\begin{array}{l}0.660- \\
1.716\end{array}$ & \\
\hline \multicolumn{5}{|c|}{$\begin{array}{l}\text { Survival (mo) } A v .(95 \% \mathrm{Cl}) \text { survival periods (months) average and } 95 \% \text { confidential interval, } H R \text { hazard } \\
\text { ratio, } P S \text { performance status, } B T S \text { bridge to surgery, SEMS self-expanding metallic stent, TADT } \\
\text { transanal decompression tube, CEA carcinoembryonic antigen, } C A 19-9 \text { carbohydrate antigen } 19-9 \text {, } \\
\text { NLR neutrophil-to-lymphocyte ratio }\end{array}$} \\
\hline
\end{tabular}

There were 34 cases with < 12 harvested lymph nodes in lymph node metastasis-negative cases (N0); therefore, these cases were excluded from the NO cases in the analyses of prognostic factors. Based on these results, we analyzed 266 cases, excluding one case of T2 and 34 cases of N0 with $<12$ harvested lymph nodes, using Cox's multivariate analysis to determine which of the following factors were related to prognosis: depth of invasion, lymph node metastasis (excluding N0 cases with $<12$ harvested lymph nodes), postoperative complications and administration of adjuvant chemotherapy (all cases). Depth of invasion, lymph node metastasis (excluding NO cases with $<12$ harvested lymph nodes), and adjuvant chemotherapy (all cases) were found to be prognostic factors (Table 4). 
Table 4

Cox's multivariate analysis for prognostic factors for relapse-free survival excluding Stage II cases with < 12 harvested lymph nodes

\begin{tabular}{|c|c|c|c|c|c|}
\hline Variable & Category & $\mathbf{n}$ & HR & $95 \% \mathrm{Cl}$ & $\begin{array}{l}p \\
\text { value }\end{array}$ \\
\hline Depth of invasion & $\mathrm{T} 3 / \mathrm{T} 4$ & $155 / 111$ & 0.461 & $\begin{array}{l}0.307- \\
0.693\end{array}$ & $\begin{array}{l}< \\
0.001\end{array}$ \\
\hline Lymph node metastasis & $\begin{array}{l}\text { N0 / N1- } \\
2\end{array}$ & $130 / 136$ & 0.523 & $\begin{array}{l}0.330- \\
0.828\end{array}$ & 0.006 \\
\hline $\begin{array}{l}\text { Postoperative complication (CD } \\
\text { classification) }\end{array}$ & $\begin{array}{l}0-1 / 2- \\
5\end{array}$ & 71/195 & 1.471 & $\begin{array}{l}0.953- \\
2.270\end{array}$ & 0.081 \\
\hline Adjuvant chemotherapy & Yes / No & $138 / 128$ & 0.606 & $\begin{array}{l}0.383- \\
0.960\end{array}$ & 0.033 \\
\hline
\end{tabular}

\section{Discussion}

Most of the studies on obstructive CRC report on the comparison with non-obstructive CRC and the efficacy of SEMS as BTS; there are few analyses on the prognostic factors of obstructive CRC. For BTS, there is no difference between decompression using temporary stoma and SEMS [24]; many recent reports and meta-analyses show no difference in long-term outcomes between BTS using SEMS and emergency surgery $[10,12,25]$. Regarding BTS using TADT, retrospective studies, which are small in size and mostly from Japan, show no difference from BTS using SEMS [26].

As prognostic factors for obstructive CRC, ASA-PS, serum albumin level $<4.0 \mathrm{~g} / \mathrm{dL}$, and depth of invasion $\mathrm{T} 4$ and R1 resection (cancer positive at cut-end) have been reported to be independent risk factors for recurrence [14]. In a comparative study between emergency surgery and BTS using SEMS, age, ASA-PS, depth of invasion, and lymph node metastasis were prognostic factors for disease-free survival [27]. A report from Japan, which is a study of 50 cases of emergency surgery and 50 cases of BTS using SEMS for Stage II/III obstructive CRC, showed that BTS and venous invasion were poor prognostic factors for RFS; BTS and T4 depth of invasion were poor prognostic factors for overall survival (OS) [28]. Long-term outcomes (OS and disease-free survival (DFS)) of emergency surgery and BTS using SEMS were equivalent, but NLR was a prognostic factor for DFS in emergency surgery. Additionally, lymphocytemonocyte ratio was a prognostic factor for OS and DFS of BTS using SEMS, as well as for OS in emergency surgery and BTS using SEMS [29]. Furthermore, a study of BTS cases using SEMS and TADT showed differences only in T4 depth of invasion and the Controlling Nutritional Status (CONUT) score for DFS, with no differences in lymph node metastasis or adjuvant chemotherapy [30].

As mentioned above, for obstructive CRC, lymph node metastasis, which is a popular prognostic factor, is not often selected. This may be due to the fact that many reports on prognostic factors for obstructive CRC were based on a small number of cases, as well as to stage migration due to inadequate lymph 
nodes dissection or a small number of harvested lymph node in emergency surgery. Furthermore, in Stage II CRC, colonic obstruction is considered an independent poor prognostic factor [31], which may weaken the impact of other prognostic factors.

In the analysis of all patients enrolled in this study, depth of invasion and postoperative complications were selected as prognostic factors; lymph node metastasis was not selected. When only Stage III cases were included, adjuvant chemotherapy was selected as a prognostic factor. Therefore, in order to exclude the possibility of stage migration due to insufficient lymph node dissection, we excluded patients with < 12 harvested lymph nodes in Stage II. Lymph node metastasis was found to be a prognostic factor in patients with a sufficient number of harvested lymph nodes. In Cox's multivariate analysis, depth of invasion, lymph node metastasis, and adjuvant chemotherapy were also selected as independent prognostic factors. The number of cases with $<12$ harvested lymph nodes were significantly higher in patients undergoing emergency surgery, which may be due to insufficient lymph node dissection because of general condition or bowel dilatation, or insufficient lymph nodes collection from the resected specimen after surgery. In Japan, it is the surgeon's job to collect the lymph nodes from the resected specimen; this work may have been inadequate during emergency surgery, which is often performed after hours. Furthermore, it is important to consider that patients who underestimated their stage due to having $<12$ harvested lymph nodes may have been disadvantaged because they should have received adjuvant chemotherapy. In addition, preoperative CEA, CA $19-9$ and NLR, which are generally considered to be prognostic factors, were not selected as prognostic factors in this study.

For this study, the following limitations should be considered. First, this study is that it was not designed to analyze the prognostic factors of obstructive CRC, but as a post-hoc analysis of a retrospective multicenter study to analyze the comparison of survival and perioperative outcomes of BTS using SEMS, TADT, and emergency surgery for LOCRC; there are cases with missing data. Second, patients who died as a consequence of SEMS placement and TADT placement remained beyond the scope of the present study. However, as no postoperative deaths after SEMS placement have been reported in any previous reporting on SEMS as BTS, the influence of this shortcoming is expected to be negligible. Third, long-term outcome was assessed by the RFS as a primary endpoint in this study. Due to the significant advances in therapeutic chemotherapy in recent years, we believe that there would be only small difference in longterm outcome based on the overall survival.

\section{Conclusion}

In LOCRC, depth of invasion, lymph node metastasis and adjuvant chemotherapy were found to be prognostic factors, and patients with $<12$ dissected lymph nodes could cause stage migration. This may result in disadvantages, such as not being able to receive adjuvant chemotherapy.

\section{Abbreviations}


ASA-PS: American Society of Anesthesiologist physical status; BTS: bridge to surgery; CA 19-9: carbohydrate antigen 19-9; CEA: carcinoembryonic antigen; CODOMO study: a retrospective multi-center observational study in Japan that comparison of the survival and perioperative outcomes of the colonic stent and the transanal decompression tube placement and emergency surgery for left-sided obstructive colorectal cancer; CRC: colorectal cancer; CROSS: ColoRectal Obstruction Scoring System; DFS: diseasefree survival; ECOG: Eastern Cooperative Oncology Group; LOCRC: left-sided obstructive colorectal cancer; NO: lymph node metastasis-negative cases; NLR: neutrophil-to-lymphocyte ratio; OS: overall survival; RFS: recurrence-free survival; SEMS: self-expandable metallic stent; TADT: transanal decompression tube

\section{Declarations}

\section{Acknowledgments}

The authors thanks H Iwasa (Department of Public Health, Fukushima Medical University) for advice and help with the statistical analyses, and Editage (www.editage.com) for English language editing. The participating members from the Japan Colonic Stent Safe Procedure Research Group are follows: Dr. K. Takayasu (Kyorin University), Dr. M Ushigome (Toho University Omori Medical Center), Dr. M Ebi (Aichi Medical University School of Medicine), Dr. Y Sumida (Kyusyu Medical Center), Dr. S Asai (Tane General Hospital), Dr. K Nasu (Tokyo Metropolitan Bokutoh Hospital), Dr. T Shiratori (Kameda Medical Center), Dr. T Kawamura (Kyoto Second Red Cross Hospital), Dr. T Ohki (Tokyo Women's Medical University), Dr. H Naota (Matsusaka Chuo General Hospital), Dr. H Matsushita (Japanese Red Cross Akita Hospital), Dr. N Watanabe (Mie Chuo Medical Center), Dr. A Kohyama (Japanese Red Cross Ishinomaki Hospital), Dr. T Kuwai (Kure Medical Center and Chugoku Cancer Center), Dr. S Saito (Yokohama Shin-Midori General Hospital), Dr. K Ohta (Higashiosaka City Medical Center), Dr. T Kimura (Tsuruga Medical Center), Dr. O Okamura (Suita Municipal Hospital).

\section{Funding}

No authors received funding or resources in relation to this article.

\section{Authors' contributions}

SE designed the study. NI, KK, YK, KA, HO, TF, HE and YS acquired the data. SE and NI confirm the authenticity of all the raw data. SE and $\mathrm{NI}$ analyzed and interpreted the data and drafted the manuscript. $\mathrm{SE}, \mathrm{NI}$ and KK performed critical revision of the manuscript. YS supervised the study. All authors read and approved the final manuscript.

\section{Availability of data and materials}

There are no data from individual authors that reach the criteria for availability.

\section{Declarations}




\section{Ethics approval and consent to participate}

Due to the retrospective design of this study conducted exclusively on patients' records, informed consent was waived. The medical ethics committee of Fukushima Medical University reviewed and approved, and this study was also registered in the Japan University Hospital Medical Information Network Clinical Trial Registry (UMIN000024488). Personal data were treated in conformity ascertained in the Declaration of Helsinki.

\section{Consent for publication}

Not applicable.

\section{Competing interests}

All authors declare that they have no competing interests in relation to the matter of this publication.

\section{References}

1. Arnold M, Sierra MS, Laversanne M, Soerjomataram I, Jemal A, Bray F. Global patterns and trends in colorectal cancer incidence and mortality. Gut. 2017;66(4):683-91. http://dx.doi.org/10.1136/gutjnl2015-310912.

2. Torre LA, Siegel RL, Ward EM, Jemal A. Global cancer incidence and mortality rates and trends-an update. Cancer Epidemiol Biomarkers Prev. 2016;25(1):16-27. https://doi.org/10.1158/10559965.EPI-15-0578.

3. Alvarez JA, Baldonedo RF, Bear IG, Truan N, Pire G, Alvarez P. Presentation, treatment, and multivariate analysis of risk factors for obstructive and perforative colorectal carcinoma. Am J Surg. 2005;190(3):376-82. https://doi.org/10.1016/j.amjsurg.2005.01.045.

4. Gunnarsson H, Holm T, Ekholm A, Olsson LI. Emergency presentation of colon cancer is most frequent during summer. Colorectal Dis. 2011;13(6):663-8. https://doi.org/10.1111/j.14631318.2010.02270.x.

5. Barnett A, Cedar A, Siddiqui F, Herzig D, Fowlkes E, Thomas CR Jr. Colorectal cancer emergencies. J Gastrointest Cancer. 2013;44(2):132-42. https://doi.org/10.1007/s12029-012-9468-0.

6. Laine L, Yang H, Chang SC, Datto C. Trends for incidence of hospitalization and death due to GI complications in the United States from 2001 to 2009. Am J Gastroenterol. 2012;107(8):1190-5. https://doi.org/10.1038/ajg.2012.168.

7. Frago R, Ramirez E, Millan M, Kreisler E, del Valle E, Biondo S. Current management of acute malignant large bowel obstruction: a systematic review. Am J Surg. 2014;207(1):127-38. https://doi.org/10.1016/j.amjsurg.2013.07.027.

8. Pisano M, Zorcolo L, Merli C, Cimbanassi S, Poiasina E, Ceresoli M, et al. 2017 WSES guidelines on colon and rectal cancer emergencies: obstruction and perforation. World J Emerg Surg. 2018;13:36. https://doi.org/10.1186/s13017-018-0192-3. 
9. van Hooft JE, Veld JV, Arnold D, Beets-Tan RGH, Everett S, Götz M, et al. Self-expandable metal stents for obstructing colonic and extracolonic cancer: European Society of Gastrointestinal Endoscopy (ESGE) guideline - update 2020. Endoscopy. 2020;52(5):389-407. https://doi.org/10.1055/a-11403017.

10. Matsuda A, Miyashita M, Matsumoto S, Matsutani T, Sakurazawa N, Takahashi G, et al. Comparison of Long-Term Outcomes of Colonic Stent as "Bridge to Surgery" and Emergency Surgery for Malignant Large-Bowel Obstruction: A Meta-Analysis. Ann Surg Oncol. 2015;22:497-504. https://doi.org/10.1245/s10434-014-3997-7.

11. Cao Y, Gu J, Deng S, Li J, Wu K, Cai K. Long-term tumour outcomes of self-expanding metal stents as 'bridge to surgery' for the treatment of colorectal cancer with malignant obstruction: a systematic review and meta-analysis. Int J Colorectal Dis. 2019;34(11):1827-38. https://doi.org/10.1007/s00384-019-03372-5.

12. Arezzo A, Forcignanò E, Bonino MA, Balagué C, Targarona E, Borghi F. ã $\square$ et al. Long-term Oncologic Results After Stenting as a Bridge to Surgery Versus Emergency Surgery for Malignant Left-sided Colonic Obstruction: A Multicenter Randomized Controlled Trial (ESCO Trial). Ann Surg. 2020;272(5):703-8. https://doi.org/10.1097/SLA.0000000000004324.

13. Amelung FJ, Borstlap WAA, Consten ECJ, Veld JV, van Halsema EE, Bemelman WA. ãulet al. Propensity scorematched analysis of oncological outcome between stent as bridge to surgery and emergency resection in patients with malignant left-sided colonic obstruction. BJS. 2019;106(8):1075-86. https://doi.org/10.1002/bjs.11172.

14. Atsushi I, Mitsuyoshi O, Kazuya Y, Syuhei K, Noriyuki K, Masashi M, et al. Long-term outcomes and prognostic factors of patients with obstructive colorectal cancer: A multicenter retrospective cohort study. World J Gastroenterol. 2016;22(22):5237-45. https://dx.doi.org/10.3748/wjg.v22.i22.5237.

15. Endo S, Kumamoto K, Enomoto T, Koizumi K, Kato H, Saida Y. Comparison of survival and perioperative outcome of the colonic stent and the transanal decompression tube placement and emergency surgery for left-sided obstructive colorectal cancer: a retrospective multi-center observational study "The CODOMO study". Int J Colorectal Dis. 2021;36(5):987-98. https://doi.org/10.1007/s00384-020-03806-5.

16. Malietzis G, Giacometti M, Askari A, Nachiappan S, Kennedy RH, Faiz OD, et al. A preoperative neutrophil to lymphocyte ratio of 3 predicts disease-free survival after curative elective colorectal cancer surgery. Ann Surg. 2014;260(2):287-92. https://doi.org/10.1097/SLA.0000000000000216.

17. Mahsuni Sevinc M, Riza Gunduz U, Kinaci E, Armagan Aydin A, Bayrak SãuUmar Gursu R, et al. Preoperative neutrophil-to-lymphocyte ratio and plateletto-lymphocyte ratio as new prognostic factors for patients with colorectal cancer. J BUON. 2016;21(5):1153-7.

18. Tsai PL, Su WJ, Leung WH, Lai CT, Liu CK. Neutrophil-lymphocyte ratio and CEA level as prognostic and predictive factors in colorectal cancer: A systematic review and meta-analysis. J Cancer Res Ther. 2016;12(2):582-9. https://doi.org/10.4103/0973-1482.144356. 
19. Matsuda A, Yamada T, Matsumoto S, Sakurazawa N, Kawano Y, Shinozuka E, et al. Pretreatment Neutrophil-to-Lymphocyte Ratio Predicts Survival After TAS-102 Treatment of Patients With Metastatic Colorectal Cancer. Anticancer Res. 2019;39(8):4343-50. https://doi.org/10.21873/anticanres.13602.

20. NCCN-Guidelines Version 2.2021. Accessed January 21, 2021. Available from: URL: http://www.nccn.org/professionals/physician_gls/pdf/colon.pdf.

21. Le Voyer TE, Sigurdson ER, Hanlon AL, Mayer RJ, Macdonald JS, Haller PJ, et al. Colon cancer survival is associated with increasing number of lymph nodes analyzed: a secondary survey of intergroup trial INT-0089. J Clin Oncol. 2003;21(15):2912-9. https://doi.org/10.1200/JC0.2003.05.062.

22. Li Destri G, Barchitta M, Pesce A, Latteri S, Bosco D, Di Cataldo A, et al. Predictive Value of the Number of Harvested Lymph Nodes and Cut-Off for Lymph Node Ratio in the Prognosis of Stage II and III Colorectal Cancer Patients. J Invest Surg. 2019;32(1):1-7. https://doi.org/10.1080/08941939.2017.1369605.

23. Clavien PA, Barkun J, de Oliveira ML, Vauthey JN, Dindo D, Schulick RD, et al. The Clavien-Dindo classification of surgical complications: five-year experience. Ann Surg. 2009;250(2):187-96. https://doi.org/10.1097/SLA.0b013e3181b13ca2.

24. Mege D, Manceau G, Bridoux V, Voron T, Sabbagh C, Lakkis Z, et al. Surgical management of obstructive left colon cancer at a national level: Results of a multicentre study of the French Surgical Association in 1500 patients. J Visc Surg. 2019;156(3):197-208. https://doi.org/10.1016/j.jviscsurg.2018.11.008.

25. Amelung FJ, Borstlap WAA, Consten ECJ, Veld JV, van Halsema EE, Bemelman WA, et al. Propensity score-matched analysis of oncological outcome between stent as bridge to surgery and emergency resection in patients with malignant left-sided colonic obstruction. Br J Surg. 2019;106(8):1075-86. https://doi.org/10.1002/bjs.11172.

26. Sato R, Oikawa M, Kakita T, Okada T, Oyama A, Abe T, et al. Comparison of the long-term outcomes of the self-expandable metallic stent and transanal decompression tube for obstructive colorectal cancer. Ann Gastroenterol Surg. 2019;3(2):209-16. https://doi.org/10.1002/ags3.12235.

27. Yang SY, Park YY, Han YD, Cho MS, Hur H, Min BS, et al. Oncologic Outcomes of Self-Expandable Metallic Stent as a Bridge to Surgery and Safety and Feasibility of Minimally Invasive Surgery for Acute Malignant Colonic Obstruction. Ann Surg Oncol. 2019;26(9):2787-96. https://doi.org/10.1245/s10434-019-07346-3.

28. Ohta K, Ikenaga M, Ueda M, lede K, Tsuda Y, Nakashima S, et al. Bridge to surgery using a selfexpandable metallic stent for stages II-III obstructive colorectal cancer. BMC Surg. 2020;20(1):189. https://doi.org/10.1186/s12893-020-00847-z.

29. Chen XQ, Xue CR, Hou P, Lin BQ, Zhang JR. Lymphocyte-to-monocyte ratio effectively predicts survival outcome of patients with obstructive colorectal cancer. World J Gastroenterol. 2019;25(33):4970-84. https://doi.org/10.3748/wjg.v25.i33.4970. 
30. Sato R, Oikawa M, Kakita T, Okada T, Abe T, Yazawa T, et al. The Controlling Nutritional Status (CONUT) Score as a prognostic factor for obstructive colorectal cancer patients received stenting as a bridge to curative surgery. Surg Today. 2021;51(1):144-52. https://doi.org/10.1007/s00595-02002066-8.

31. Okuda Y, Shimura T, Yamada T, Hirata Y, Yamaguchi R, Sakamoto E, et al. Colorectal obstruction is a potential prognostic factor for stage II colorectal cancer. Int J Clin Oncol. 2018;23(6):1101-11. https://doi.org/10.1007/s10147-018-1307-2.

\section{Figures}

\section{CODOMO study}

A retrospective multi-center observational study in Japan that comparison of the survival and perioperative outcomes of the colonic stent and the transanal decompression tube placement and emergency surgery for leftsided obstructive colorectal cancer.

\section{Including criteria}

1. Primary left-sided colorectal cancer (Stage II/III, location: Descending colon, Sigmoid colon, Upper rectum), January 2010 - December 2014

2. Colonic obstruction due to colorectal cancer with CROSS sore $0 / 1$

3. Age $20-80$ year-old at radical surgery

4. Without neoadjuvant chemotherapy/radiotherapy

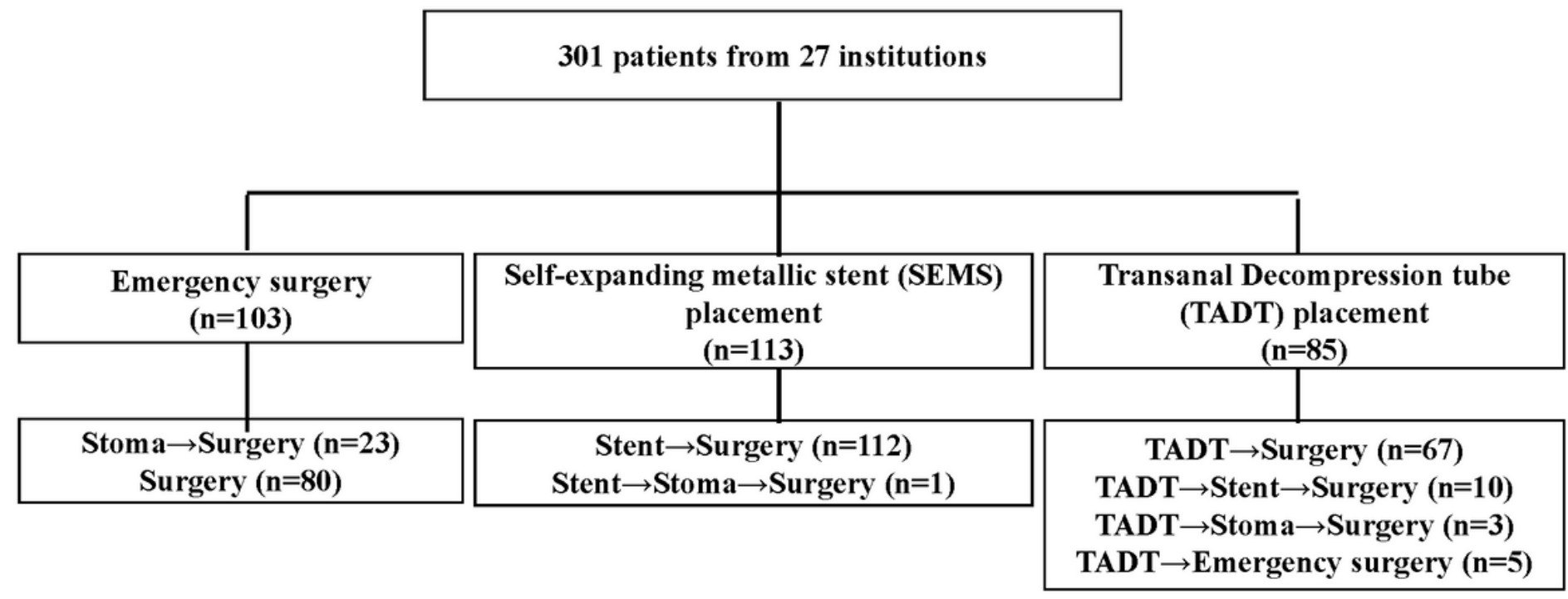

Figure 1

Study participants selection flowchart of CODOMO study 
A

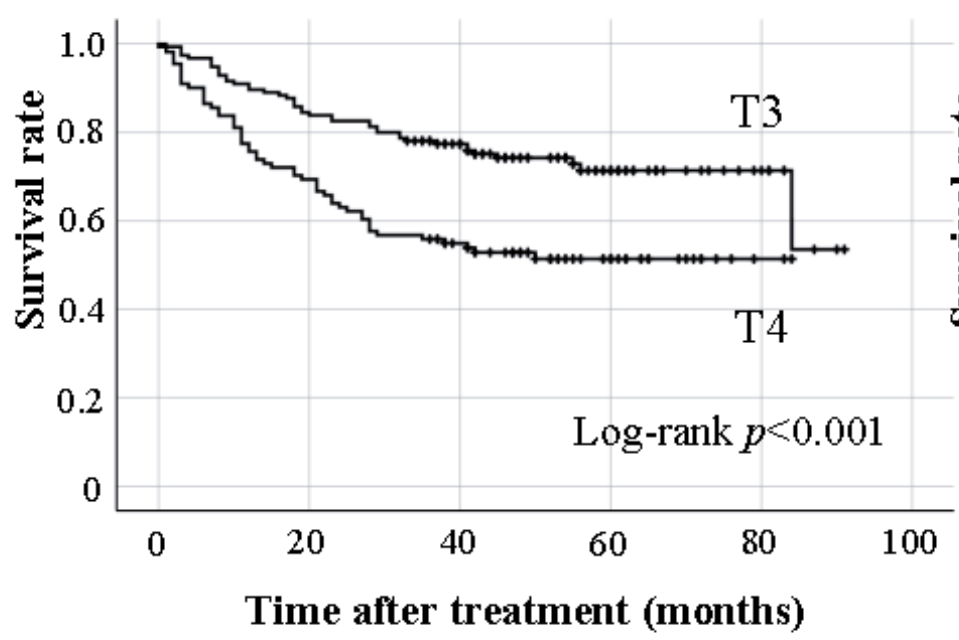

Number at risk

$\begin{array}{rrrrr}\text { T3 } & 153 & 130 & 108 & 38 \\ \text { T4 } & 111 & 77 & 55 & 32\end{array}$

B

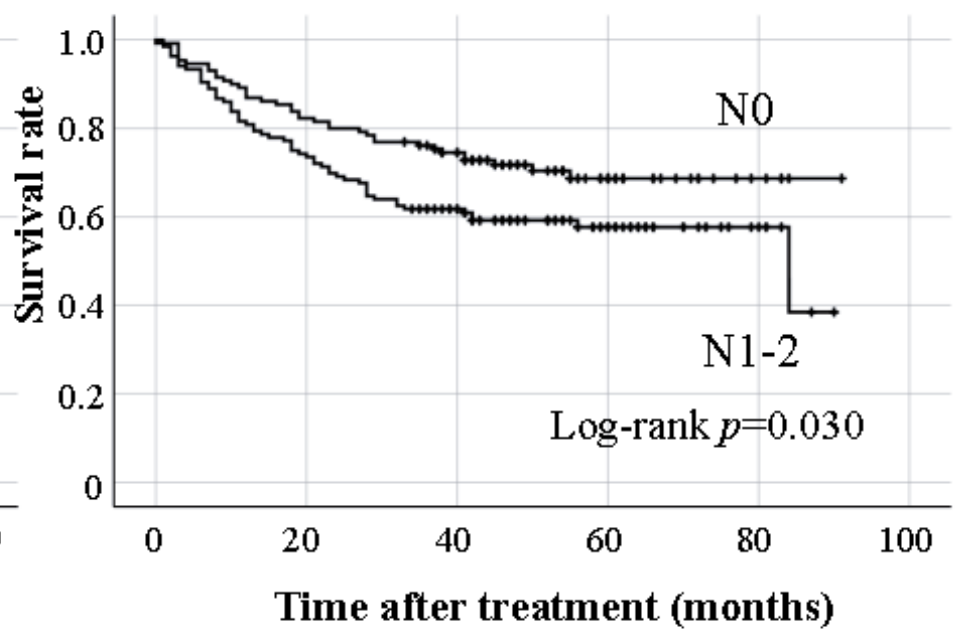

Number at risk

$\begin{array}{llllll}\text { No } & 130 & 107 & 86 & 21 & 5 \\ \text { N1-2 } & 135 & 100 & 74 & 28 & 6\end{array}$

\section{Figure 2}

Kaplan-Meier curves presenting relapse-free survival rate in at risk patients with T3 or T4 depth of invasion (A), and that with N0 or N1-2 lymph node metastasis (B) 